\title{
The Evolution and Current Manufacturing Practice Applied to the traditional Dress of Women in Ghana
}

\author{
Mercy Afi Kuma-Kpobee \\ Department of Fashion Design, Ho Polytechnic, P.O. Box HP 217, Ho, Ghana \\ Email:kpobee2@yahoo.com
}

\begin{abstract}
Traditional dress for women in Ghana, known as "slit and kaba", previously required no standardised sizing and fit, but as this dress has undergone an evolution and taken on more western features, the fit and manufacturing quality have become increasingly important. This paper evaluates the effect of the evolution of the slit and kaba on the current manufacturing processes adopted by the micro and small scale enterprises in Ghana. A qualitative approach was adopted to collect data in three metropolitan centres in Ghana from dressmakers of the traditional dress. An inductive approach through the grounded theory technique was utilised to analyse the data and the findings revealed that the traditional dress has undergone a considerable change in fit and form. The over reliance on trainee apprentices as workers has affected the quality of garments produced in relation to standardisation. It is also evident that most of the dressmakers rely on domestic equipment which is rudimentary in terms of technological development. This paper highlights the importance of skills and adequate equipment in the achievement of fit and quality in the area of garment manufacture in Ghana.
\end{abstract}

Keywords: Garment manufacture; Quality standards; Fit; Traditional dress; Evolution.

\section{Introduction}

It has been established that the primary influence of dress type worn by individuals in a society is culture (Maynard, 2004; Barnard, 2002). Dress types may be classified into two groups; namely, western or contemporary and non-western dress forms. Western dresses are considered as fashion and characterized by change whereas non-western dresses are often associated with local cultures (Rovine, 2004). Nonwestern dresses are often called tribal, native, folk, ethnic, indigenous or traditional (Rovine, 2004; Rabine, 2002; Eicher and Sumberg, 1995), and are seen as unchanging, slow to change or with few modernising influences (Eicher and Sumberg, 1995). However, there is evidence that the dual usage of traditional and western dress sometimes results in the hybrid of other dress forms (Dogbe, 2003; Salm and Falola, 2002) such as the traditional New Year's dress of the Hmong Americans (Lynch, 1999) and the men's traditional long sleeve shirts of Malaysia (Maynard, 2004).

The Ghanaian slit and kaba used for both formal and informal occasions by women is viewed as a representation of social relations and ideology through the use of traditional fabrics with symbolic connotation (Dogbe, 2003; Salm and Falola, 2002; Arthur and Rowe, 2001; Littrell, 1980). These fabrics function as a non-material culture as they signify the values and beliefs of the different ethnic groups. Based on the above, the slit and kaba could be classified as a traditional dress in Ghana. The slit (ankle length skirt) and kaba (blouse), a-three-piece ensemble is considered as an adaptation of the indigenous two piece wrapper that women wore before coming into contact with European traders and colonizers. It is worth stating that Ghana has a dual system of dress owing to colonisation, and this system is the traditional and western.

The garment manufacturing sector plays an important role in employment generation in Ghana, and for this reason, the government in a bid to promote this sector launched the President's Special Initiative (PSI) in 2001 (Kufour, 2008). It is estimated that garment manufacturing constitutes about $60 \%$ of the informal sector employment in Ghana (Boateng, 1996). However, the informal nature of this sector and the demand for custom made garments have affected the development of the garment industry in Ghana with the absence of or existence of a few large scale 
existence of a few large scale industries (Hoefter, 2001). This negative trend is confirmed by Ampofo (2002) who reported that there were 138 medium and large scale garment and textile industries producing ready-to-wear garments in Ghana in 1979 but this number had reduced to 72 by 1995 .

Most of these industries collapsed as a result of problems such as poor finishing of products, inability to meet export orders that are associated with mass production and lack of quality and conformity to standards. Hoefter (2001), however, is of the view that the problems of low productivity could be attributed to the lack of management skills by Ghanaians for larger firms as these firms are mainly managed by foreign expatriates.

The importance of the micro and small scale enterprises (SME) is recognised as being significant in the development of the African as well as the Ghanaian economy. As a result, the role of this sector is considered as critical in promoting economic growth and in generation of employment towards poverty reduction among the Ghanaian population. Quartey (2006) and Chimieloweic (1995), observed that the garment industries in Ghana consists of numerous micro and small scale dressmakers in a form of sole proprietorships and are mainly involved in the production of made-to-measure garments for individuals and employ about 1-30 workers. It is known from past works (Fluitman, 1992; Anon. 2004; Liimatainen, 2004, World Bank SAR, 1993) that most employees in the informal sector in Ghana acquired their skills through informal apprenticeships.

The above authors suggest that this type of informal training appears to have insufficient theoretical foundations which may affect the quality of skills acquired. Kufour (2008), also concurs that the SME sector is characterised by low levels of education and training of the self-employed in Ghana. As a result, tailors and dressmakers trained through this system in Ghana are sometimes referred to as roadside dressmakers to indicate the lack of structure, and often they have limited or basic skills in pattern making as the freehand cutting technique (method of cutting out patterns directly from the fabric) is mainly taught (Fianu and Zentey, 2000). The slit and kaba, however, is mainly produced as a made-to-measure garment by dressmakers and tailors in the micro scale informal enterprises.

Although, the slit and kaba is widely used and are important in the socio-economic development of Ghana, its research has received very little attention. It is also evident from the absence of relevant literature that the garment industry is not receiving the necessary attention for it to develop as it lacks research in the areas of management and product development as done in advanced countries. But as the slit and kaba has evolved and taken more western features, the fit and manufacturing quality has become increasingly important. As a result, human and physical resources are important factors that can promote the future development and change in the garment industry in Ghana. The focus of this research is therefore:

1. To examine the evolution of the slit and kaba in relation to fit and form.

2. To evaluate the current manufacturing practices adopted by the SME's and their implication on the quality standards.

\section{Method}

A qualitative approach was adopted to collect data in three metropolitan centres in Ghana, namely, Accra, Kumasi and Takoradi from dressmakers of the traditional dress. The data collection strategies utilised were observation and semi-structured interviews necessary to the understanding of the production methods and the equipment used.This sampling procedure has been described as non-probability purposive sampling technique in which the elements of the population are not deliberately given equal opportunity to be included in the sample. In this regard, 25 dressmakers and tailors of the slit and kaba were observed in their respective workshops and interviewed at a later date to help the researcher further understand some of the manufacturing processes.

For the purpose of this study which is focused on the SMEs in the garment manufacturing sector, the definition by the Ghana Statistical Service (2002), which uses the number of employees was adopted with a modification to include micro firms as follows:-

1. Micro firms with up to 5 employees

2. Small with between 6-9 employees

3. Medium with more than 10 employees

The definition in terms of number of employees was selected based on the fact that the garment manufacturing industry is considered as labour intensive and, therefore, relies on the number of employees as most of the processes involved are still not mechanised. The definition adopted for the research is deemed appropriate as suggested by Storey (1994) because garment manufacturing in Ghana 
is mainly done in the informal sector by the SMEs with low technological development (Quartey, 2006).

In order to observe the current production process of the slit and $\mathrm{kaba}$ in relation to the management of anthropometric data and standardisation, a semi-structured checklist was developed to direct the observation procedure. The themes for the observation were developed based on existing literature as identified in terms of quality standards in relation to garment manufacture as in the observation guide. Similarly, the profiles of the dressmakers and their employees' were also observed for the researcher to ascertain their implication on the utilisation of the anthropometric data in relation to the fit and quality of the garments.

\section{Findings}

An inductive approach through the grounded theory technique was utilised to analyse the data from the semi-structured interviews and the observation.

\subsection{Evolution of slitand kaba}

The traditional slit and kaba is mostly made in local or indigenous designs and fabrics such as wax prints and kente which are associated with the cultural beliefs and practices in Ghana. The fabrics appear not to have undergone much change over the years, hence, the slit and kaba's classification as a traditional dress.

The findings revealed that in terms of evolution of the traditional dress, the slit and kaba has undergone significant changes in relation to design features and usage. It is evident that several factors such as western fashion trends, magazines, fashion shows and technological advancement have contributed to the change in the form and fit of the traditional dress.

A participant stated that "The western media has influenced this change and people have realised that western styles can be adapted to the slit and kaba so they are copying it" manufacturer (Manufacturer 04). Most of the participants are of the view that the slit and kaba has been transformed over the years and looks more like western dress which is linked to the above listed factors as may be observed from the following statements; but I think it's the people who try to interpret the African print as it will not be too different from the known western type of garment; and if you look at what has happened over the past 10 years, you can see that there is the reduction in the gap of what the western type of dress looks like and the slit and kaba as a traditional dress of today. I think they are becoming more and more alike and the designers are trying to interpret the African fabric in a way that will not be too different from the western garment which appears to be the trend; and people are now trying to make the slit and kaba look like a western garment as the world is becoming and becoming smaller and people don't want to dress more differently from what is worn outside; so there is a convergence as we go along (Manufacturer 010).

Western culture in a way has also affected this shift as the things that happen outside are reflected in what we do here as people tend to copy the western styles which are seen in our traditional dress now. You know, in the past, we did not have a lot of media houses and fashion shows but now they have become very common (Manufacturer 012).

The styles have just evolved and the loose ones have given way to the fitted ones; and I also think people have become more conscious of their figures and want to show more of them. In a way, technology has also contributed to this change as previously we could not access the type of machines we have now, and you can get whatever you want just that they are expensive (Manufacturer 08)

The above statements are a clear indication of the dynamism of culture and its link to the accessibility of the global world. As a result, the slit and kaba which used to be semi-fitted to loose and tend to conceal most of the body parts has changed in to fit as it has become a hybrid of traditional and western dress forms as observed from these excerpts:-

The slit for instance is no more straight but very shaped to conform to the body and even the kaba has wider varieties with fitted and wider necklines, with smaller sleeves, strapped or strapless tops. The kaba now almost clings to the body unlike the past when we had the loose type of kaba which is now out of fashion and reserved for the elderly (Manufacturer 02).

The results also suggest that the design of the slit and kaba has become more fashionable as compared to the design a decade ago, and it has led to increased usage. The participants attributed this fashionable design to western designs and the availability of different fabrics that are more colourful and attractive. It is worth noting that western dress is used 
as every- day wear for most average Ghanaians, therefore, western influence could affect the usage as the traditional dress has taken on more western features as explained in the following:

they have changed from classic to more daring styles as any style at all can be made from the traditional cloth as halter necks and so on, and the styles are more fashionable and the slit as well. Because younger people are wearing it now and the older ones have also changed a little, so there is an increase in usage as you can custom make your dress...... (Manufacturer 014).

In relation to the change in form and fit of the slit and kaba, the participants are of the view that the current change in the form and fit requires advanced skills in order for the dressmaker to produce well fitted garments that mould properly to the body. This view supports the findings that the slit and kaba has evolved in terms of fit; therefore, the requirement for its production necessitates advanced techniques as seen from the following excerpts:

almost all the designs are fitted so you need proper skills to mould the garment. The loose kaba did not require much skill. With the fitted kaba you need to consider the figure of the client, try to enhance the good and minimize the bad (Manufacturer 08).

\section{Observation findings}

The observation was carried out on the companies profile (Table 1), equipment in the workshop, construction techniques and how patterns for the garments are obtained. Knowledge in obtaining and utilisation of anthropometric data were also observed. The use of trainee apprentices was evident and although majority of them provided labour, they were not paid for. Most of the enterprises with the exception of three had more trainee apprentices than full time employees or professionals and this may affect the quality of work produced. The target groups for all the dressmakers are similar in terms of age classifications which suggest that the traditional dress remains an important part of the Ghanaian culture. The majority (23) of the dressmakers were women and their ages ranged from 24-50 years. In terms of education, three had acquired a university degree, four a Higher National Diploma from the polytechnics, two with technical school certificate, four vocational school qualifications and the majority (12) acquired training through apprenticeship in the informal sector.

Table 1

Profile of companies.

\begin{tabular}{|c|c|c|c|c|c|c|}
\hline \multirow{2}{*}{$\begin{array}{l}\text { Manu } \\
\text { Code }\end{array}$} & \multirow[t]{2}{*}{ Education } & \multirow[t]{2}{*}{ Sex } & \multicolumn{2}{|c|}{ Number of workers } & \multirow{2}{*}{$\begin{array}{l}\text { Target } \\
\text { group }\end{array}$} & \multirow[t]{2}{*}{ Age } \\
\hline & & & Full time & Apprentice(s) & & \\
\hline $\mathrm{AC} 01$ & HND & $\mathrm{F}$ & 7 & 16 & $18-60$ & 45 \\
\hline $\mathrm{AC} 03$ & Technical & $\mathrm{F}$ & 5 & 15 & $16-55$ & 37 \\
\hline $\mathrm{AC} 05$ & Apprenticeship & $\mathrm{F}$ & 1 & 10 & $18-65$ & 31 \\
\hline $\mathrm{AC} 07$ & Apprenticeship & $\mathrm{F}$ & 1 & 9 & $18-60$ & 49 \\
\hline AC09 & Apprenticeship & $\mathrm{F}$ & 25 & 5 & $18-60$ & 47 \\
\hline AC011 & University & $\mathrm{F}$ & 21 & 2 & $18-65$ & 30 \\
\hline AC013 & HND & M & 4 & 12 & $16-70$ & 50 \\
\hline $\mathrm{AC} 015$ & University & M & 7 & 5 & $18-60$ & 28 \\
\hline $\mathrm{AC} 017$ & Vocational & $\mathrm{F}$ & 1 & 18 & $18-60$ & 27 \\
\hline AC019 & Apprenticeship & $\mathrm{F}$ & 2 & 14 & $18-65$ & 45 \\
\hline AC021 & Apprenticeship & $\mathrm{F}$ & 4 & 6 & $18-65$ & 43 \\
\hline $\mathrm{AC} 023$ & Vocational & $\mathrm{F}$ & 4 & 7 & $18-65$ & 38 \\
\hline K025 & Apprenticeship & $\mathrm{F}$ & 2 & 10 & $18-65$ & 31 \\
\hline K027 & Apprenticeship & $\mathrm{F}$ & 3 & 7 & $18-65$ & 44 \\
\hline K029 & HND & $\mathrm{F}$ & 1 & 10 & $16-65$ & 36 \\
\hline K031 & Vocational & $\mathrm{F}$ & 2 & 13 & $18-65$ & 32 \\
\hline
\end{tabular}




\begin{tabular}{llllrll} 
K033 & Apprenticeship & F & 2 & 11 & $18-65$ & $\mathbf{3 1}$ \\
K035 & Apprenticeship & F & 3 & 12 & $18-60$ & $\mathbf{4 6}$ \\
K037 & Apprenticeship & F & 3 & 8 & $18-60$ & $\mathbf{4 4}$ \\
K039 & University & F & 4 & 15 & $18-60$ & $\mathbf{3 8}$ \\
T041 & Apprenticeship & F & 1 & 11 & $15-55$ & $\mathbf{2 6}$ \\
T043 & Apprenticeship & F & 1 & 9 & $16-70$ & $\mathbf{5 0}$ \\
T045 & HND & F & 1 & 10 & $18-60$ & $\mathbf{4 8}$ \\
T047 & Technical & F & 1 & 11 & $18-65$ & $\mathbf{4 7}$ \\
T049 & Vocational & F & 3 & 9 & $18-60$ & $\mathbf{4 8}$ \\
\hline
\end{tabular}

$$
\mathrm{n}=25
$$

\subsection{Equipment}

In order for the researcher to have an insight into the production of the slit and kaba, the type and number of equipment owned by the dressmakers were observed and are presented in Table 2.The result revealed that most of the dressmakers had one or more industrial sewing machine with the exception of six who rely mainly on domestic electric and hand sewing machines. In terms of specialised equipment, it was evident from the observation that only one of the dressmakers had industrial cutting equipment whereas the other twenty four relied on basic cutting out shears.

Table 2

Sewing equipment in the workshop

\begin{tabular}{llllll}
\hline Manufacturer's & $\begin{array}{l}\text { Industrial } \\
\text { Cede }\end{array}$ & $\begin{array}{l}\text { Domestic } \\
\text { Electric Sewing }\end{array}$ & $\begin{array}{l}\text { Domestic Hand } \\
\text { Manual Sewing } \\
\text { Machine }\end{array}$ & $\begin{array}{l}\text { Industrial } \\
\text { cutters }\end{array}$ & $\begin{array}{l}\text { Embroidery } \\
\text { machines }\end{array}$ \\
\hline AC001 & 3 & 2 & 20 & - & - \\
AC003 & 2 & 4 & 15 & - & - \\
AC005 & 1 & 0 & 16 & - & - \\
AC007 & 0 & 4 & 10 & - & - \\
AC009 & 17 & 10 & 5 & 1 & 2 \\
AC011 & 10 & 15 & 6 & - & 1 \\
AC013 & 8 & 3 & 7 & - & 1 \\
AC015 & 8 & 5 & 0 & - & 1 \\
AC017 & 3 & 0 & 18 & - & - \\
AC019 & 0 & 2 & 14 & - & - \\
AC021 & 2 & 2 & 6 & - & - \\
AC023 & 2 & 0 & 9 & - & - \\
K025 & 4 & 0 & 8 & - & - \\
K027 & 1 & 4 & 5 & - & -
\end{tabular}




\begin{tabular}{lllrll} 
K029 & 0 & 4 & 8 & - & - \\
K031 & 1 & 2 & 13 & - & - \\
K033 & 1 & 1 & 14 & - & - \\
K035 & 2 & 4 & 12 & - & - \\
K037 & 3 & 2 & 6 & - & - \\
K039 & 1 & 1 & 10 & - & - \\
T041 & 0 & 1 & 9 & - & - \\
T043 & 0 & 1 & 10 & - & - \\
T045 & 0 & 1 & 11 & - & - \\
T047 & 3 & 0 & 9 & - & - \\
T049 & 3 & 2 & 15 & & - \\
\hline
\end{tabular}

$\mathrm{n}=25$

The result also indicated that none of the dressmakers had an industrial pressing equipment and pattern making software. However, in terms of other auxiliary equipment, a few of the dressmakers had embroidery machines. The majority of the dressmakers relied more on domestic basic equipment than advanced industrial equipment. As a result of the type of equipment owned, most of the dressmakers may be classified as home dressmakers, and, therefore, cannot handle large volume of orders. All the dressmakers in this study have moved out from the home, however, the continued reliance on domestic equipment may be the issue of lack of funds.

\subsection{Construction techniques}

In this section, the results of the on-site observation of construction techniques are presented which include the sewing process of the slit and kaba such as seam construction and finishes that are applied to the garment.

In terms of laying and cutting out procedures, it was observed that most of the dressmakers prepare the fabric before cutting out by looking for flaws, and pressing the fabric in order to remove unwanted creases.

Most of the dressmakers (20) do not match motifs in the fabric before cutting out is done which results in ill-matched motifs. This may be a result of the fact that most of the dressmakers are ignorant about motif/pattern placement and its effect on the aesthetic quality of the garment.
It was generally observed that, cutting out on the right grain line of the fabric was determined by the motifs in the fabric as well as the desired effect. It was observed that most of the dressmakers do not have knowledge, especially, in cutting on the straight grain (warp thread).

However, most of the motifs in the traditional local fabrics are placed in the direction of the weft grain and border designs which make cutting on the warp grain impossible. This is because the selvedge of the fabric when wrapped around the body or sewn into a slit is meant to be at the waist and ankle levels. None of the dressmakers use any powered cutting tools.

The basic scissors is used for all the cutting out process. The cutting out was mainly done by the owner or a manager and a book of the measurement of all their customers and sometimes with the sketches of selected styles and fabric swatch is kept.

The garment production system is characterised by the flat method which joins garment pieces together. In terms of shaping materials processes, (lining, underlining, interlining and interfacing), the underlining technique which was mainly used is achieved by the dressmaker handling the garment and shaping fabrics together as one. This method of utilisation of shaping materials is easier, faster and more convenient in terms of garment alteration and in terms of the level of difficulty compared to the full lining technique. In terms of seam finishes, closed seams were mainly used and the raw edges were finished with the overlocking machine. In addition to the above the following were also observed: 
1. Large side seam allowances up to $7 \mathrm{~cm}$ were left on the kaba.

2. Some of these wide side seam allowances were finished as closed seams and, therefore, affect the fit of garments especially at the side seams.

3. Not much attention was paid to the finishing of the wrong sides of the garments.

4. Kaba was cut without the shaping of the side seams, but the shaping was done after the darts and panel seams were stitched.

5. A lot of the fabric was wasted when free hand cutting was used and motifs were poorly aligned.

6. Garments were mainly produced by the trainee apprentices under the supervision of the owner managers or senior apprentices, and this sometimes affected the quality of the garments.

7. There are no standardised procedures that were followed for the manufacture of the slit and kaba

\subsection{The use of anthropometric data}

It was observed that all the dressmakers measured their customers in order to produce made-to-measure garments. The number of measurements varied although the key dimensions (bust, waist and hip girths) were taken by all of them. The findings in Table 3 represent the frequency of the measurements that were taken for the manufacture of slit and kaba. Among these measurements, the bust girth, waist girth, lower hip girth, front waist length, wrist and the side waist to ankle were taken by all the dressmakers.

Table 3

Frequency of dressmakers and the number of body measurements

\begin{tabular}{lll}
\hline & Body Dimensions & $\begin{array}{l}\text { Frequency of } \\
\text { Measurements Taken } \\
(\mathbf{n}=\mathbf{2 5})\end{array}$ \\
\hline $\mathbf{1}$ & Weight & $\mathbf{0}$ \\
$\mathbf{2}$ & Height & $\mathbf{0}$ \\
$\mathbf{3}$ & Neck Girth & $\mathbf{1}$ \\
$\mathbf{4}$ & Shoulder Width & $\mathbf{7}$ \\
$\mathbf{5}$ & Shoulder Length & $\mathbf{1 4}$ \\
$\mathbf{6}$ & Across Chest & $\mathbf{1 1}$ \\
$\mathbf{7}$ & Chest Girth & $\mathbf{2}$ \\
$\mathbf{8}$ & Across Back & $\mathbf{1 8}$ \\
$\mathbf{9}$ & Bust Girth & $\mathbf{2 5}$
\end{tabular}

\begin{tabular}{llr}
$\mathbf{1 0}$ & Under Bust & $\mathbf{1}$ \\
$\mathbf{1 1}$ & Waist Girth & $\mathbf{2 5}$ \\
$\mathbf{1 2}$ & Lower Hip Girth & $\mathbf{2 5}$ \\
$\mathbf{1 3}$ & Upper Hip Girth & $\mathbf{0}$ \\
$\mathbf{1 4}$ & Thigh Girth & $\mathbf{1}$ \\
$\mathbf{1 5}$ & Front Waist Length & $\mathbf{2 5}$ \\
$\mathbf{1 6}$ & $7^{\text {th }}$ Cervical to Waist & $\mathbf{9}$ \\
$\mathbf{1 7}$ & Upper Arm Girth & $\mathbf{2 1}$ \\
$\mathbf{1 8}$ & Wrist Girth & $\mathbf{2 5}$ \\
$\mathbf{1 9}$ & Acromion to Wrist & $\mathbf{1}$ \\
$\mathbf{2 0}$ & Side waist to Knee & $\mathbf{1 6}$ \\
$\mathbf{2 1}$ & Side waist to Ankle & $\mathbf{2 5}$ \\
\hline
\end{tabular}

However, one would expect that since most of them produce fitted kaba, measurements such as the shoulder length and width, across chest and back and the back length measurements should be utilised in order to achieve good fit.

It was observed that 20 out of the 25 dressmakers solely obtained patterns for their garments through the free hand cutting technique. However, five dressmakers utilise flat patterns for more complicated designs. The observation revealed that the free hand cutting technique, although fast and convenient has several disadvantages such as fabric wastage as the designs are directly plotted on the fabric and mistakes are not readily detected for immediate corrections. This technique can lead to damaged fabrics, inability to re-use pattern for production and finally, it does not promote standardisation of similar designs and sizes.

\section{Discussion}

Previous research has established that traditional dress is not static but may undergo changes over time (Eicher, 1995), and others have found that some of these dresses have been hybridised with components from other cultures (Maynard, 2004; Salm and Falola, 2002; Lynch, 1999; Matthews, 1979) in today's globalised world.

The current study confirms that the fit of the traditional dress has significantly changed over the past decades as it has taken more western features influenced by foreign fashion trends in vogue. The change in fit is attributed to western dress which is used alongside the traditional dress for formal work and other non-traditional functions.. The preference for fitted garments suggests that the importance placed 
on women's body forms globally seems to be present in Ghana as the traditional dress seeks to accentuate the contours of the figure (Dogbe, 2003).

The symbolic meaning of the traditional dress has played an important role in its continued use and evolution as found in the current study. There is evidence that other African fabrics are currently used for the traditional dress. And although, traditional motifs continued to be used for the wax prints, the colour schemes are currently more vibrant compared to the traditional subdued ones previously used. The findings, however, indicates that the use of traditional wax print fabric is still the most popular as seen in Littrell's (1980) study. It is interesting to note that the use of ceremonial hand woven kente has also gained popularity although these fabrics are very expensive as compared to the traditional wax prints.

The current study has shown that majority of the firms in this study operate at the micro category (one to five workers) level in terms of firm size which is consistent with other surveys (Sowa et al. 1992) and are predominately female owned. It is worth noting that only three and two out of the twenty-five firms could be classified as small and medium size categories respectively which imply that the production of the traditional dress is predominantly done at the micro level.

This is seen in the number of full time employees although most of the enterprises have several trainee apprentices. Past research has documented the use of trainee apprentices as a source of labour in the informal manufacturing sector in Ghana (Mensah, Tribe and Weiss, 2007; Morton, 2004; Fianu and Zentey, 2000; Kayanula and Quartey, 2000) as also found in this study.

It was evident that the use of unskilled labour compromised the quality standards as the production of garments is generally classified as labour intensive (Zwane, Richards and Edmond, 2002). Formal education is a prerequisite for sewing as the ability to read and write is important in obtaining and utilisation of accurate anthropometric data. It was revealed that majority of the dressmakers had received training in free hand cutting (Fianu and Zentey, 2000; Fianu and Acquaah-Harrison, 1999) which has several drawbacks.

Given the importance of transforming body measurements into patterns, one would expect these dressmakers would have acquired adequate training in flat pattern making which is critical to garment fit. In fact this research has rather shown the opposite as most of the ressmakers in the current study do not have adequate skills in pattern making as the basic requirement for garment fit.

The number of body measurements taken by each dressmaker also varied significantly although the key dimensions (bust, waist and hip) were taken by all the dressmakers. This suggests that the key dimensions are important measurements in garment construction as they form the basis (Bougourd, 2007) for garment size.

The fact that some of these measurements are not taken have important implications in relation to garment fit. From the literature, it is evident that in order for a dressmaker to achieve a good fit of clothes it is essential to have a good relationship between the garment and the contours of the body (Chen, 2007) by obtaining the appropriate measurements. Istook and Hwang (2001) suggest it is impossible to deal with consumers garment fit issues without a set of accurate and adequate body measurements.

A significant number of the enterprises observed operating at the micro level had simple domestic equipment which was very unsatisfactory (Fianu and Zentey, 2000) and implies that only basic sewing procedures are undertaken. It is, therefore, reasonable for the researcher to conclude that most of the enterprises in the micro category observed in this study may be classified as home dressmakers in terms of equipment and full time employees. It is evident from the findings that Fidler and Webster's definition of the informal sector as a small enterprises that "'use low technology methods of production and management"' (1996, p. 5) is applicable to this study. Several researchers have also observed that the SME development is constrained by numerous factors such as finance, equipment and technology and access to international markets (Steel and Webster, 1992; BaahNuakoh and Teal, 1993; Aryeetey, 1994).

It appears that the lack of industrial equipment by most of the dressmakers hinders large-scale production and efficiency in terms of their meeting deadlines for garment orders by their customers. The use of ultra-modern equipment is necessary in replacing manual machines in order to facilitate the production process as this will in turn promote the garment industry in particular and the economy as a whole. According to Glock and Kunz (2005), the development of intrinsic quality such as fit requires a large investment in materials, equipment and skills to increase efficiency and accuracy. It appears that most of these enterprises started as home businesses which initially required less capital for start-up. 
Another hindrance to micro-small scale enterprises is the lack of access to funds or credit (Fening et. al, 2008) for industrial equipment and expansion. Although most of the owner-managers expressed the availability and the need for modern equipment in the interviews, it appears that most of them may be hindered by lack of funds to actually purchase this equipment. The findings of the current study are contrary to those of Fianu and Zentey (2000) in which garment manufacturers in their study expressed the unavailability of sewing equipment and spare partsfor their enterprises.

\section{Change in production methods}

Based on the findings of this study, the current production methods were evaluated in relation to fit and quality standards. The study has, therefore, developed a process map for the current manufacturing practice, the concept for the future and the strategy for transition as presented in Figure 1.

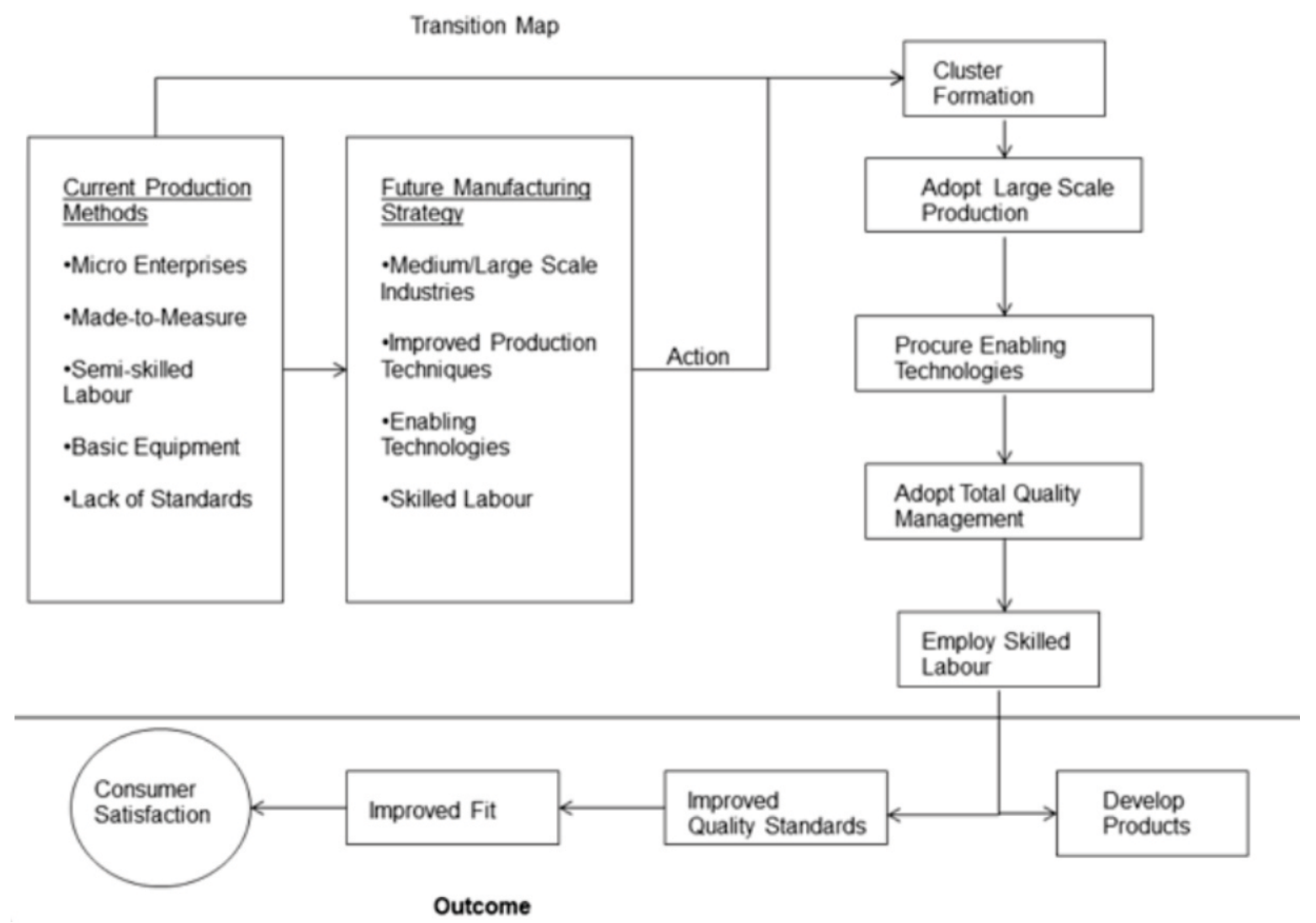

Fig 1: Transition map

\section{Conclusion}

As observed from this study, the evolution of the slit and kaba requires advanced production methods, industrial equipment and skilled labour in order for dressmakers to meet the current demands of the change in form and fit.

As identified in this study, majority of the enterprises operate at the micro level. However, firm sizes are very important as they demonstrate the capabilities of the individual enterprises and require the expansion from micro category to medium or large scale levels by the formation of partnerships and clusters in order for dressmakers to pull resources together. The adoption of this approach would also enable the banking institutions to grant these enterprises long term loans needed for the expansion. Although micro size enterprises have their own advantages such as quick decision making to respond to issues, it may be limited in terms of capital requirements needed for the expansion of the enterprise.

The over reliance on semi-skilled trainee apprentices as the labour source for these enterprises is likely to compromise the quality of the garments produced. The production process of garments is considered as labour intensive; therefore, trained and skilled 
workers are important to assemble garments properly in order to achieve the desired quality standards. The fit of garments does not only depend on accurate body measurements but also an efficient garment assembly process which eliminates sewing errors such as seam puckering and incorrect matching of notches. Skill development is, therefore, necessary in the adoption of large scale production strategy which is based on the efficiency of both employees and the equipment used.

\section{References}

Ampofo, V. O., (2002). Ghana's Textile/Garment Industry, Industrial Development and Investment Division (Ministry of Trade and Industry- Ghana) at:http://www.intracen.org/worldtradenet/docs/ whatsnew/atc_lesotho_november2002/country_p aper_ghana.pdf (accessed 18 October, 2004).

ANON., (2004). Informal Education Strategies for Skills Acquisition in West Africa: A Review of Literature and Recent Significant Research Results.Retrieved from:http://www.adeanet.org/wgnfe/publication s/abel/abel3.html (accessed 18 October, 2004).

Aryeetey, E., (1994). Financial Integration and Development in Sub-Sabaran Africa: A Study of Informal Finance in Ghana (Working Paper No. 76). ODI, London.

Baah-Nuakoh, A. and Teal, F., (1993). Economic Reforms and the Manufacturing Sector in Ghana, Report for the African Regional Program of Enterprise Development, World Bank, Washington, DC.

Bougourd, J. ,(2007). 'Sizing Systems, Fit Models and Target Markets' in Sizing in Clotbing.Ashdown, S.P. (Ed), Woodhead Publishing, Cambridge, Chapter 4, pp.108-151.

Barnard, M., (2002).Fashion as Communication $\left(2^{\text {nd }}\right.$ Edn),Routledge Publications.

Chen, C., (2007). Fit Evaluation Within the Made-ToMeasure Process, International Journal of Clotbing Science and Technology, Vol.19, No. 2,pp.131-144.

Chimieloweic, R., (1995). Rehabilitation of the Textiles and Garment Industry. SI/GHA/94/802-Advisory Mission Technical Report, Post 11-52. Unpublished Draft Report. The Ghana Government by UNIDO acting as Executive Agency for UNDP.
Dogbe, E., (2003).Unraveled Yarns: Dress, Consumption, and Women's Bodies in Ghanaian Culture, Fashion Theory, Vol.14, No. (3/4),pp. 377-396.

Eicher, J.B., (1995). 'Introduction: Dress as Expression of Ethnic Identity' in Eicher, J.B. (Ed) Dress and Ethnicity, Berg Publisher Limited Oxford, pp.1-5

Fening, F.A., Pesakovic, G. and Amaria, P., (2008).Relationship Between Quality Management Practices and the Performance of Small and Medium Size Enterprises (SMEs) in Ghana, International Journal of Quality and Reliability Management, Vol.25, No.7,pp. 694-708.

Fianu, A.G. and Zentey, E.A., (2000).Problems of LargeScale Fashion Designers in Accra, Ghana,Journal of Consumer Studies E Home Economics, Vol.24, No.2,pp. $128-136$.

Fianu, D.A.G. and Acquah-Harrison, P., (1999).Apprenticeship System of Wayside Seamstresses in Selected Neighbourhoods in Accra, Ghana, The Journal of Asian Regional Association for Home Economics, Vol. 6, No.4,pp. 245-254.

Fidler, P. and Webster, L., (1996).The Informal Sector and Microfinance Institutions in West Africa, World Bank Document No. 12048, Washington, DC.

Fluitman, F., (1992). Traditional Apprenticeship in West Africa: Recent Evidence and Policy Options. (Discussion Paper No. 34). Retrieved from: <URL:http://www.celcee.edu.abstracts/c199603 68.html?version $=$ print $\quad$ (accessed 18 October, 2004).

Ghana Statistical Service (2002).2000 Population E Housing Census: Summary Report of Final Results.

Hoefter, A.F., (2001). The Competitiveness of Ghana's Industry (Unpublished $\mathrm{PhD}$ thesis) Dissertation Nr. 2494, Difo-Druck, Bamberg, Germany.

Istook, C.L. and Hwang, S.J., (2001).3D Body Scanning Systems with Application to the Apparel Industry, Journal of Fashion Marketing and Management, Vol. 5, No. 2,pp. 120-132. 
Kufour, A.A., (2008). International Forum on Sustainable Private Sector Development. Nova Scotia, Canada, $19^{\text {th }}-21^{\text {st }}$ June, 2008: GIMPA Business School, Ghana.

Kayanula, D. and Quartey, P. ,(2000). The Policy Environment for Promoting Small and Medium-Sized Enterprises in Ghana and Malawi. Finance and Development Research Programme, (Working Paper No. 15) Institute of Development Policy and Management, University of Manchester, Crawford House, Precinct Centre, Oxford Road, Manchester M139 GH.

Liimatainen, M. R., (2004). InFocus Programme on Skills, Knowledge and Employability (Informal Economy Series), International Labour Office$\mathrm{G}$ e $\mathrm{n}$ e $\mathrm{va}$. R e $\mathrm{t} \mathrm{r}$ i e ved f $\mathrm{r}$ o $\mathrm{m}$ : http://www.ilo.org/public/english/employment/ infeco/download/literature.pdf(accessed 24 October, 2004).

Littrell, M. A., (1980). Home Economists as CrossCultural Researchers: A Field Study of Ghanaian Clothing Selection, Family and Consumer Sciences Research Journal, Vol. 8,pp. 307-317.

Lynch, A., (1999). Dress, Gender and Cultural Change: Asian American and African American Rites of Passage, Berg Publishers, New York.

Matthews, L.B., (1979).Relationship Between Traditionalism of Dress and Social Values of Ghanaian Women,Home Economics Research Journal, Vol.7, No. 6,pp. 89-98.

M a y nard, M., (2004), Dress and Globalisation, Manchester University Press, Oxford Road, Manchester.
Mensah, J.H., Tribe, M. and Weiss, J., (2007). The SmallScale Manufacturing Sector in Ghana: A Source of Dynamism or of Subsistence Income? Journal of International Development, Vol. 19, pp.253-273.

Quartey, P., (2006). "The Textiles and Clothing Industry in Ghan" in Herbert Jauch / Rudolf Traub-Merz (Eds.) The Future of the Textiles and Clotbing Industry in Sub-Sabaran Africa. Bonn: Friedrich-Ebert-Stiftung.

Salm, S.J. and Falola, T., (2002).Culture and Customs of Ghana, (Culture and Customs of Africa), Greenwood Press, 88 Post Road, Westport, CT 06881, USA.

Sowa, N.K., Baah-Nuakoh, A., Tutu, K. and Osei, B., (1992).Small Enterprises and Adjustment: The Impact of Ghana's Economic Recovery on Small and Medium Enterprises, Overseas Development Institute/University of Ghana, London/Accra.

Steel, W.F. and Webster, L.M., (1992).How Small Enterprises Have Responded to Adjustment, Industry and (Series Paper, No. 33) The World Bank Industry and Energy Department, Washington, DC.

Storey, D., (1994).Understanding the Small Business Sector, Routledge.

World Bank Report (1993). Ghana 2000 and Beyond; Setting the Stage for Accelerated Growth and Poverty Reduction. ix, xi, 10, 52-53, 64, 489, African Regional Office. Western African Department, World Bank, Washington, DC, USA.

Zwane, P., Richards, L. and Edmond, M., (2002). Apparel Production in Swaziland: The Need for Industry Education. Clothing and Textile Research Journal, Vol.20,No. 4,pp. 256-281. 